\title{
Molecular characterization and epidemiology of the highly pathogenic avian influenza $\mathrm{H5N1}$ in Nigeria
}

\author{
F. O. FASINA ${ }^{1,2 *}$, S. P. R. BISSCHOP ${ }^{2}$, T. M. JOANNIS ${ }^{1}$, L. H. LOMBIN ${ }^{1}$ \\ AND C. ABOLNIK ${ }^{3}$ \\ ${ }^{1}$ National Veterinary Research Institute, Vom, Nigeria \\ ${ }^{2}$ Poultry Reference Centre, Faculty of Veterinary Science, University of Pretoria \\ ${ }^{3}$ ARC-Onderstepoort Veterinary Institute, Pretoria, South Africa
}

(Accepted 2 June 2008; first published online 17 July 2008)

\section{SUMMARY}

Avian influenza caused infection and spread throughout Nigeria in 2006. Carcass samples (lung, liver, spleen, heart, trachea and intestine) from the different regions of Nigeria were processed for virus isolation. Infective allantoic fluids were tested for avian influenza viruses (AIV) and Newcastle disease virus using monospecific antisera. Thirty-five isolates were generated and characterized molecularly using the haemagglutinin gene. The molecular analysis indicated that different sublineages of the highly pathogenic avian influenza (HPAI) H5N1 viruses spread throughout Nigeria. We compared the Nigerian isolates with others from Africa and results indicated close similarities between isolates from West Africa and Sudan. Some of the analysed viruses showed genetic drift, and the implications of these for future epidemiology and ecology of avian influenza in Africa require further evaluation. The spread of primary outbreaks was strongly linked to trade (legal and illegal), live bird markets, inappropriate disposal, and poorly implemented control measures. No strong correlation existed between wild birds and HPAI $\mathrm{H} 5 \mathrm{~N} 1$ in Nigeria.

Key words: Avian influenza H5N1.

\section{INTRODUCTION}

A highly pathogenic avian influenza (HPAI) subtype H5N1 outbreak was reported for the first time on the African continent in February 2006 in Nigeria [1]. The disease devastated the poultry sector of the economy, especially in the north-central region of Nigeria. Although several control measures including culling, movement restrictions, compensation and improved biosecurity were implemented by the authorities to

* Author for correspondence: Dr F. O. Fasina, Viral Research Division, National Veterinary Research Institute, Vom, Nigeria. Tel: + 2347033128949 .

(Email: daydupe2003@yahoo.co.uk) limit the spread, the country continues to report outbreaks and new premises are being infected [2]. At present, the Nigerian outbreaks have been confirmed in 22 states with estimated mortalities of 945862 birds (chickens, ducks, ostriches, turkeys, doves, pigeon, emus and geese) at substantial cost [3]. As of 2008, only one case of HPAI H5N1 in humans has been reported from Lagos, South-West Nigeria.

Ducatez and co-workers [4] previously identified three HPAI H5N1 virus strains circulating in Nigeria, which had close genetic relationships with viruses from Kurgan, Astrakhan and Egypt; while Salzberg et al. [5] demonstrated that African isolates have common ancestry with viruses from Europe and the 


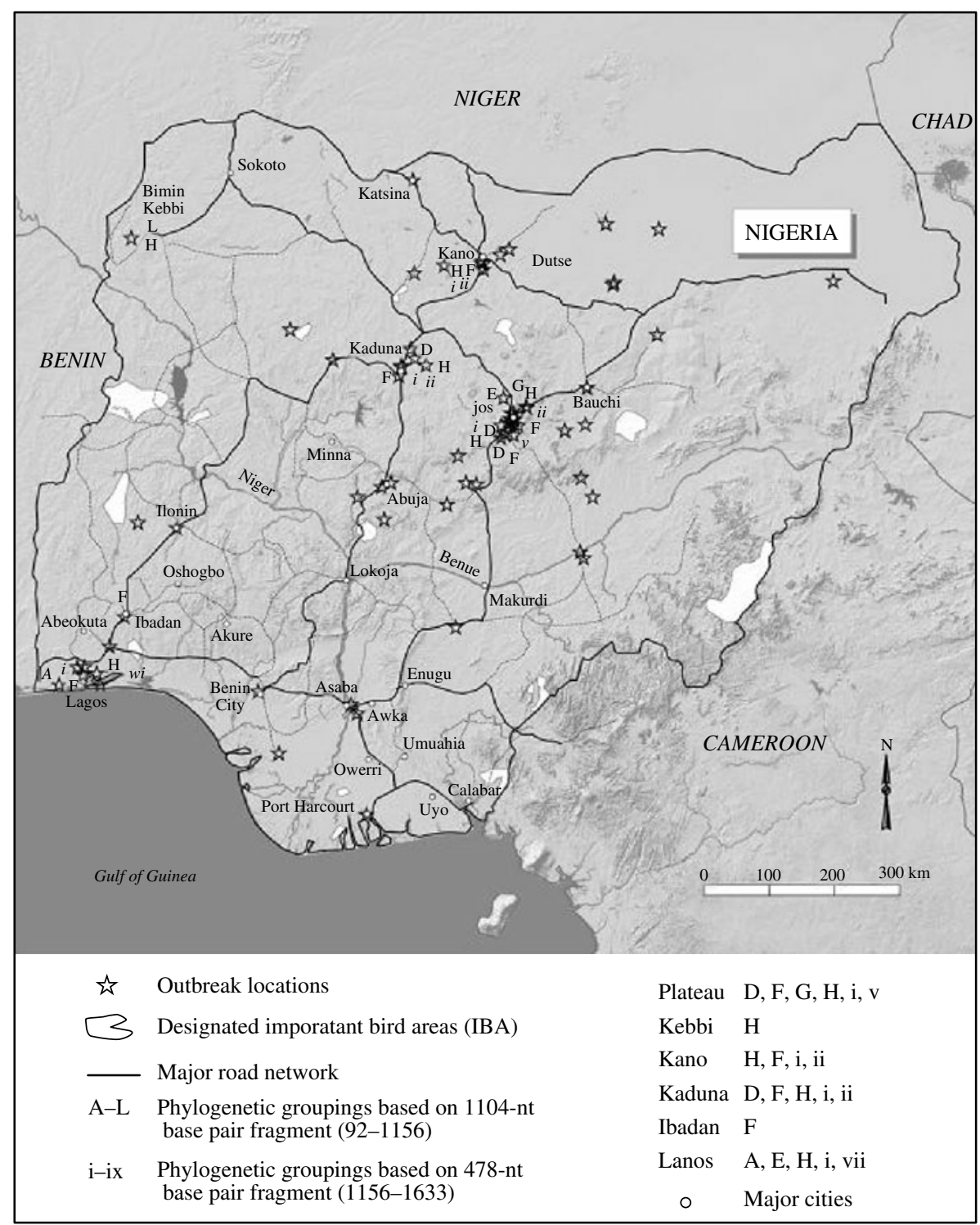

Fig. 1. Map of Nigeria showing the important bird areas, origins of viruses used in the study, road networks and all outbreak areas.

Middle East. They suggested the possibility of wild migratory birds being responsible for the introduction of these viruses into the country. However, these workers were limited to a few geographic areas and a limited number of African H5N1 viruses were considered in their analyses, respectively. Nigeria alone recorded almost 200 HPAI H5N1 outbreaks in different locations between January 2006 and January 2007 and it may be important to evaluate the role of trade imports and other risk factors in addition to those from migratory birds (Fig. 1).

The aims of the present study were to determine the epidemiological origin(s) of avian influenza H5N1 in Nigeria, by analysing the haemagglutinin
(HA) genes from different regions of Nigeria, and to assess the possible roles of human activities, poultry movement within the country, trade imports and migratory birds in the epidemiology of HPAI in Nigeria.

\section{MATERIALS AND METHOD}

Tissue samples (lung, liver, spleen, heart, trachea and intestine) were collected at outbreak locations or were submitted by the public to the National Veterinary Research Institute. During 2006-2007, a total of 1205 suspected outbreaks were investigated and 299 isolates of HPAI H5N1 were recovered. 


\section{Viruses}

Pooled tissue homogenates were treated with isotonic phosphate-buffered saline supplemented with penicillin, streptomycin, gentamycin and amphotericin B (PSGA) according to standard protocols [6].

Infective allantoic fluids were harvested and tested for avian influenza viruses (AIV) and Newcastle disease virus using monospecific antisera. Aliquots were inactivated using lysis buffer (MagNA Pure LC $^{\circledR}$, Roche Applied Sciences, Mannheim, Germany). Further molecular analyses were conducted at the Agricultural Research Council-Onderstepoort Veterinary Institute, South Africa.

\section{RNA extraction and RT-PCR}

Viral RNA was extracted from lysates using Trizol LS $^{\circledR}$ reagent (Invitrogen Life Technologies, Carlsbad, CA, USA) or a MagNA Pure LC $^{\circledR}$ total nucleic acid isolation kit and device (Roche Applied Sciences) according to the manufacturers' instructions.

\section{First-strand cDNA synthesis}

Reverse transcription was performed on $5 \mu 1$ extracted viral RNA with $3 \mathrm{pMol}$ of the vGEN oligonucleotide, that anneals to the $5^{\prime}$ terminal sequence of the HA gene segment, $60 \mathrm{IU}$ of M-MLV reverse transcriptase (Promega, Madison, WI, USA) and $8 \mathrm{IU}$ of ribonuclease inhibitor (Amersham, Biosciences, Piscataway, NJ, USA) at $42{ }^{\circ} \mathrm{C}$ for $90 \mathrm{~min}$.

In other cases, one-step RT-PCR was performed by adding a 20 -min $42{ }^{\circ} \mathrm{C}$ incubation step to the thermocycling profile prior to PCR.

\section{PCR}

Full length HA genes were amplified using $20 \mathrm{pMol}$ forward 5'-AGCAAAAGCAGGGGW-3' and reverse 5'-AGTAGAAACAAGGGTG-3' primers; $5 \mathrm{U} / \mu 1$ Ex Taq polymerase (Takara Biotech, Shiga, Japan) and $2.5 \mathrm{~mm}$ deoxyribonucleic acids (dNTPs) on an Eppendorf Mastercycler ${ }^{\circledR}$ (Eppendorf AG, Hamburg, Germany). A partial HA gene region was amplified for some Nigerian H5N1 isolates for which a full-length gene could not be obtained, presumably due to RNA degradation.

RT-PCR amplicons were visualized by electrophoresis on $1 \%$ agarose gels (Hispanagar, Burgos, Spain), excised and the DNA extracted with a
QIAquick ${ }^{\circledR}$ Gel Extraction kit (Qiagen, Hilden, Germany).

\section{DNA sequencing and phylogenetic analysis}

Template DNAs were quantified using a NanoDrop ${ }^{\circledR}$ ND-1000 Spectrophotometer (NanoDrop Technologies Inc., Wilmington, DE, USA). Cycle sequencing reactions were performed using the forward and reverse primers used for PCR, and a third oligonucleotide 5'-CCACCTATATTTCCGTTGGGAC$3^{\prime}$ designed to span the mid region of the HA gene, and the BigDye ${ }^{\circledR}$ Terminator version 3.1 chemistry (PerkinElmer/Applied Biosystems, Foster City, CA, USA), according to manufacturer's instructions. Amplicons were sequenced on a 3130 Genetic Analyzer (PerkinElmer/Applied Biosystems).

Blast homology searches available from NCBI [7] were used to identify 76 closely related sequences representing wide species, geographical and spatial distributions and including all HPAI H5N1 sequences available from Africa. Multiple alignments were performed using Clustal W (see EBI database $[8,9]$ ). Pairwise nucleotide sequence identities were calculated using Bioedit ${ }^{\mathbb{R}}$. The region of the HA genes of Nigerian viruses analysed corresponds to nucleotides 92-1633 of the complete 1730 nucleotide proteinencoding region of the HA gene of HPAI H5N1 viruses.

Phylogenies were reconstructed (see Supplementary Fig. 1, available online) using the neighbour-joining method in MEGA 3.1 software [10], the Kimura two-parameter sequence evolution model, and 1000 bootstrap replicates to assign confidence levels to branches. We considered a bootstrap value of $>70$ to be a strong indicator of a phylogenetic relationship.

\section{Accession numbers}

Gene sequences of selected viruses were deposited in the Genbank under the accession numbers EF631164-EF631187.

\section{RESULTS}

\section{Virus isolation}

In the period between January 2006 and December 2007, a total of 299 isolates of HPAI H5N1 were 
Table 1. List of Nigerian HPAI H5N1 virus isolates included in the study

\begin{tabular}{|c|c|c|c|c|}
\hline & Name & Species affected & Location, state & $\begin{array}{l}\text { Date of report/ } \\
\text { collection }\end{array}$ \\
\hline 1 & A/chicken/Nigeria/VRD35/2006 & Commercial layer chicken & $?$ & 2 Feb. 2006 \\
\hline 2 & A/chicken/Nigeria/VRD42/2006 & Commercial layer chicken & Katako Area, Plateau & 9 Feb. 2006 \\
\hline 3 & A/chicken/Nigeria/VRD44/2006 & Commercial layer chicken & Rikkos, Plateau & 9 Feb. 2006 \\
\hline 4 & A/chicken/Nigeria/VRD49/2006 & Commercial layer chicken & $\begin{array}{l}\text { Dahol Giring (Forest), } \\
\text { Plateau }\end{array}$ & 14 Feb. 2006 \\
\hline 5 & A/chicken/Nigeria/VRD83/2006 & Chicken & Naraguta, Plateau & 17 Feb. 2006 \\
\hline 6 & A/chicken/Nigeria/VRD91/2006 & Commercial layer chicken & University Quarters & 18 Feb. 2006 \\
\hline 7 & A/chicken/Nigeria/VRD130/2006 & Commercial layer chicken & Apollo Cresent, Plateau & 24 Feb. 2006 \\
\hline 8 & A/chicken/Nigeria/VRD130b/2006 & Commercial layer chicken & Apollo Cresent, Plateau & 24 Feb. 2006 \\
\hline 9 & A/chicken/Nigeria/VRD145/2006 & Pullet chicken & Sabon Barki, Plateau & 26 Feb. 2006 \\
\hline 10 & A/chicken/Nigeria/VRD146/2006 & Commercial layer chicken & Katako Market, Plateau & 26 Feb. 2006 \\
\hline 11 & A/chicken/Nigeria/VRD111/2006 & Commercial layer chicken & Katako Market, Plateau & 27 Feb. 2006 \\
\hline 12 & A/chicken/Nigeria/VRD157/2006 & Commercial layer chicken & Zaria Road, Plateau & 27 Feb. 2006 \\
\hline 13 & A/chicken/Nigeria/VRD165/2006 & Commercial layer chicken & Chwelnyap (Congo), Plateau & 28 Feb. 2006 \\
\hline 14 & A/chicken/Nigeria/VRD184/2006 & Vulture & Vom, Plateau & 4 Mar. 2006 \\
\hline 15 & A/chicken/Nigeria/VRD193/2006 & Commercial layer chicken & Mando, Kaduna & 8 Mar. 2006 \\
\hline 16 & A/chicken/Nigeria/VRD200/2006 & Pullet chicken & Jos, Plateau & 7 Mar. 2006 \\
\hline 17 & A/chicken/Nigeria/VRD203/2006 & Commercial layer chicken & Kaduna, Kaduna & 8 Mar. 2006 \\
\hline 18 & A/chicken/Nigeria/VRD216a/2006 & Commercial layer chicken & $\begin{array}{l}\text { Cooperative Farm, } \\
\text { Agege, Lagos }\end{array}$ & 10 Mar. 2006 \\
\hline 19 & A/chicken/Nigeria/VRD218/2006 & Commercial layer chicken & Rikkos, Plateau & 11 Mar. 2006 \\
\hline 20 & A/chicken/Nigeria/VRD219/2006 & Commercial layer chicken & $\begin{array}{l}\text { Old Airport Junction, } \\
\text { Plateau }\end{array}$ & 13 Mar. 2006 \\
\hline 21 & A/chicken/Nigeria/VRD244/2006 & Commercial layer chicken & Bukuru, Plateau & 30 Mar. 2006 \\
\hline 22 & A/JWP/Nigeria/VRD252/2006 & Wild species & Jos Wildlife Park & 3 Apr. 2006 \\
\hline 23 & A/turkey/Nigeria/VRD262/2006 & Turkey & Ungwan Dosa, Kaduna & 6 Apr. 2006 \\
\hline 24 & A/chicken/Nigeria/VRD284/2006 & Commercial layer chicken & Apata, Plateau & 13 Apr. 2006 \\
\hline 25 & A/chicken/Nigeria/VRD286/2006 & Commercial layer chicken & Jos, Plateau & 16 Apr. 2006 \\
\hline 26 & A/chicken/Nigeria/VRD311/2006 & Commercial layer chicken & Bukuru, Plateau & 26 Apr. 2006 \\
\hline 27 & A/chicken/Nigeria/VRD340/2006 & Commercial layer chicken & Zaria Road, Plateau & 5 May 2006 \\
\hline 28 & A/turkey/Nigeria/VRD345/2006 & Turkey & Rukuba, Plateau & 8 May 2006 \\
\hline 29 & A/chicken/Nigeria/VRD368/2006 & Commercial layer chicken & Dogon Dutse, Plateau & 20 May 2006 \\
\hline 30 & A/pigeon/Nigeria/VRD370/2006 & Pigeon & Vom, Plateau & 20 May 2006 \\
\hline 31 & A/chicken/Nigeria/VRD403/2006 & Commercial layer chicken & Molete Market, Oyo & 6 June 2006 \\
\hline 32 & A/duck/Nigeria/VRD418/2006 & Duck & Dogon Karfe, Plateau & 8 June 2006 \\
\hline 33 & A/chicken/Nigeria/VRD419/2006 & $\begin{array}{l}\text { Local and commercial } \\
\text { layer chicken }\end{array}$ & Dogon Karfe, Plateau & 8 June 2006 \\
\hline 34 & A/chicken/Nigeria/VRD457/2006 & Commercial layer chicken & Ijegun, Lagos & 28 June 2006 \\
\hline 35 & A/guinea fowl/Nigeria/VRD005/2007 & Guinea fowl & Kebbe, Sokoto & 5 Jan. 2007 \\
\hline
\end{tabular}

recovered from 26 states of the federation while a total of 96 isolates of Newcastle disease virus were recovered.

Based on diversities of geographical spreads, times of occurrences and avian species infected by HPAI H5N1, a total of 35 isolates of HPAI H5N1 viruses (HPAIV H5N1) were further cultivated in 9- to 11-day-old specific pathogen-free (SPF) embryonating chicken eggs using standard procedures [6], at the Viral Research Laboratory, National Veterinary
Research Institute, Vom, Nigeria. A list of cultivated viruses are given in Table 1.

\section{Phylogenetic analysis}

Six sublineages were identified amongst the Nigerian H5 genes based on branching order, molecular markers (nucleotide and amino acid) and bootstrap values. These six sublineages (A, D, E, F, G, H) (Supplementary Fig. 1) were distributed within clade 
2.2, previously described, which co-circulated during the outbreaks of HPAI H5N1 in Nigeria in 2006 [4]. Of all the viruses analysed in this study, sublineages A- $\mathrm{J}$ belong to large clade 2.2, sublineage $\mathrm{K}$ belongs to clade 2.3.4, sublineage $\mathrm{L}$ belongs to clade 1 and A/chicken/Shanxi/2/2006 (H5N1) belongs to clade 7 [11].

The Nigerian viruses in sublineage $\mathrm{A}(n=3)$ were isolated around 24 February 2006 in the early course of HPAI H5N1 infection in Nigeria. This group of viruses showed a close genetic similarity to the Egyptian viruses which were isolated at about the same time, i.e. 17 February, 2006. Whereas Nigerian viruses differ in positions $\mathrm{Lys}^{30}$ and $\mathrm{Glu}^{200}$, Egyptian viruses contained a unique $\mathrm{Ser}^{250}$ residue (data not shown).

The viruses in sublineage $\mathrm{D}(n=6)$ were all isolated in the first and second weeks of February 2006 at three different locations within the same local government area (LGA) (Jos North). This phylogenetic grouping is partially supported by a shared $\mathrm{Arg}^{339}$ residue in the partial amino-acid alignment (data not shown). This $\mathrm{Arg}^{339} \rightarrow$ Gly replacement occurred at the cleavage site. These viruses were amongst the first isolated from the outbreaks in northern Nigeria. Although isolate A/chicken/Nigeria/VRD286/2006 (H5N1) grouped in sublineage D and was also found in the same LGA, it contained a $\mathrm{Leu}^{225} \rightarrow$ Met substitution and precipitated outbreaks some 8 weeks after the related viruses.

These earlier sublineages of Nigerian viruses (sublineage D) together with viruses from Burkina Faso, Cote d'Ivoire, and Sudan represent the widest diversity in terms of geographical location and host species among all of the viruses studied. This sublineage spread in the West African subregion and up towards North Africa (Sudan). It is interesting to note that Sudanese viruses are not phylogenetically closely related to viruses from the infected geographical neighbour, Egypt (sublineage A). Ducatez et al. [12] indicated that A/chicken/Sudan/1784/2006 has the maximum percentage nucleotide difference $(1.8 \%$ when compared to A/chicken/Egypt/5611NAMRU3$\mathrm{AN} / 2006$ ) among the African viruses but the significance of this is unclear. Species affected by this sublineage D include commercial chickens, ducks, hooded vultures, turkeys and guinea fowl (Numida meleagris).

The isolates in sublineage $\mathrm{E}(n=2)$ were isolated from South-West Nigeria and had also been previously reported [4]. These strains precipitated outbreaks around the first week of March 2006. This sublineage was characterized by the following aminoacid markers: $\mathrm{Ile}^{273}$ and $\mathrm{Ala}^{279}$.

Sublineage $\mathrm{F}(n=14)$ caused severe outbreaks in northern Nigeria. These viruses were isolated between 9 February and 6 June 2006. Most of these viruses shared $100 \%$ nucleotide sequence identities, except for A/chicken/Nigeria/VRD218/2006 (H5N1) and A/chicken/Nigeria/VRD219/2006 (H5N1) which shared an $\mathrm{Ile}^{205}$ residue in the partial aminoacid alignment (Supplementary Fig. 1). Sublineage F strains, namely A/chicken/Nigeria/VRD42/2006 (H5N1), A/chicken/Nigeria/VRD200/2006 (H5N1), A/chicken/Nigeria/VRD146/2006 (H5N1), A/chicken/ Nigeria/VRD91/2006 (H5N1), A/chicken/Nigeria/ VRD157/2006 (H5N1), A/chicken/Nigeria/VRD130/ 2006 (H5N1), A/chicken/Nigeria/VRD130b/2006 (H5N1), A/chicken/Nigeria/VRD244/2006 (H5N1) all have $\mathrm{Val}^{190} \rightarrow \mathrm{Ile}$ and $\mathrm{Ala}^{201} \rightarrow \mathrm{Thr}$ substitutions. This group of viruses had a strong link to markets and major poultry trade routes within the country and shared common recent ancestors with viruses found in ducks from Niger Republic, which had its first outbreak around the same time, i.e. 13 February, 2006 [2]. There were previous reports by the Food and Agricultural Organization (FAO) [13] linking outbreaks in northern Nigeria to those reported in Gallaya Riga village, Niger Republic. The data presented here confirms this report.

Sublineage $\mathrm{G}(n=4)$ was involved in outbreaks in local turkeys, free-range chickens, and commercial birds. These outbreaks occurred between 13 April in commercial birds and 8 June in local turkeys and free-range chickens, respectively. These viruses were phylogenetically related, sharing a Gly ${ }^{286}$, although A/chicken/Nigeria/VRD284/2006 (H5N1) has $\mathrm{Val}^{40} \rightarrow$ Asp and $\mathrm{Ala}^{351} \rightarrow \mathrm{Thr}$ substitutions. They occurred within the same region in Plateau state.

Sublineage $\mathrm{H}(n=18)$ contains viruses isolated from market areas, distant locations and a diverse species of birds (chicken, vulture, wildlife, guinea fowl, pigeon and local breeds of domesticated birds). They are most probably linked to the movement of poultry and poultry products, as most of the outbreaks occurred when movement restrictions were absent or relaxed. Infected hatcheries and markets may also have played a role in the dissemination of these viruses. The amino-acid sequences at the HA cleavage site, i.e. ${ }^{337} \mathrm{Pro}, \mathrm{Gln}, \mathrm{Gly}, \mathrm{Glu}, \mathrm{Arg}, \mathrm{Arg}, \mathrm{Arg}$, Lys,Lys,Arg,Gly ${ }^{347}$ was identical to that of viruses from Western Europe, Western Asia and Africa 
(Egypt, Burkina Faso, Cote d'Ivoire, and Niger) with only a Gly ${ }^{339} \rightarrow$ Arg substitution in A/chicken/Nigeria/ VRD35/2006(H5N1), A/chicken/Nigeria/VRD44/ 2006(H5N1) and A/chicken/Nigeria/VRD83/2006 (H5N1). Other African viruses in group D A/chicken/ Sudan/1784-7/06(H5N1), A/chicken/Sudan/2115-10/ 06(H5N1), A/chicken/Sudan/2115-12/06(H5N1) also have a Gly ${ }^{341} \rightarrow$ Arg substitution at this cleavage site (data not shown).

While Salzberg et al. [5] indicated that A/chicken/ Nigeria/1047-62/2006 was a reassortant generated in Africa; we identified four related strains (according to homology with the haemagglutinin proteins) A/chicken/Nigeria/VRD35/2006, A/chicken/Nigeria/ VRD44/2006 A/chicken/Nigeria/VRD83/2006 and A/chicken/Nigeria/VRD286/2006. The further spread of this group of viruses in the poultry population and possibly mammals may increase the pandemic alert level as suggested by the World Health Organization.

\section{DISCUSSION}

Prior to this study, only 15 Nigerian isolates of avian influenza $\mathrm{H} 5 \mathrm{~N} 1$ were present in the public sequence depositories (GenBank and EMBL). This study has enriched the pool of the HPAI H5N1 viruses deposited from Nigeria. A total of 35 newly isolated viruses were subjected to molecular characterization and the haemagglutinin sequences of these viruses (identical sequences excluded) were deposited in the GenBank. This dataset currently represents the widest spatio-temporal and species related diversities from Nigeria publicly available.

The current phylogenetic analyses agreed with previous reports [4] that Nigeria was infected by multiple sources of the $\mathrm{H} 5 \mathrm{~N} 1$ virus. The phylogenetic relationships and time of occurrence of viruses in sublineage A indicates a high probability of shared epizootics with Egypt. These viruses were limited to South-West Nigeria (Lagos) and did not spread further.

The West African subregion operates as a freetrade zone with poor quarantine and border controls. It is highly likely that trans-border movements of humans along with trade of poultry and poultry products and weak biosecurity played a significant role in the spread of viruses in sublineage $\mathrm{D}$, which contained a large cluster of geographically diverse viruses from infected African nations. The Sudanese outbreaks possibly occurred as a result of the initial shared infection between Nigeria and Egypt, which Sudan later contracted through long-distance poultry or poultry products movement, probably from Nigeria. Although the Cameroonian virus sequences were not included in this study due to unavailability, the outbreaks in that country roughly coincided with the time period of early infection in Nigeria (21 February).

Sublineages A and D were some of the earliest HPAI H5N1 viruses to affect the continent and the groups of outbreaks caused by these viruses were restricted to the commercial poultry in Nigeria and were similarly found early in some other West African countries and Sudan (between 1 March and 1 April). This strongly suggests that imported infected commercial stock may have been the source of outbreak.

The importance of the live bird markets (LBM) in the spread of the virus in West Africa is particularly evident in the present study. The viruses in sublineage $\mathrm{H}$ (infecting vultures, pigeon, guinea fowl, free-range chicken and other birds from a wildlife park) were geographically and chronologically dispersed in Nigeria following infection of the LBMs, inappropriate disposal methods and isolation of the virus in the LBMs and hatcheries. Field data which are supported by these phylogenetic analyses indicated that outbreaks caused by this group of viruses were found in locations as distant as $954 \mathrm{~km}$ from an infected LBM infection. Previous studies have similarly confirmed the role of wet markets, LBMs and movement of poultry and poultry products without recourse to biosecurity in the viral ecology and spread of avian influenza and other viruses [14-16].

Poultry movement in Nigeria follows a particular trend: local guinea fowl, ducks, turkeys, local freerange chickens and spent hens are usually moved towards the south of the country especially around the festive period (Christmas, Easter, Eid-el-Fitri and Eid-el-Maulud). Day-old-chicks and input supplies are the major poultry-related products moved up north. These movements and trend lines of dates of occurrences of outbreaks could explain the wide geographical diversities in outbreaks caused by the sublineages originating from northern Nigeria and the highly restricted spread of those from SouthWest Nigeria (sublineages $\mathrm{A}$ and E). Furthermore, it was reported that Nigeria continued to import poultry and poultry products from contaminated zones in 2005 despite the ban on such importation and these imports are distributed throughout the country [17]. 
Vultures probably contracted infection from disposed carcasses and viscera. Infection of pigeons may have occurred due to their co-habitation with infected free-range chickens, turkeys and ducks, as suggested by the timeline of infections and the phylogram. The infection of wildlife park birds occurred in early April, a period that roughly coincides with Easter and Eid-el-Kabir and increasing human movement to the park. The park is situated in the epicentre of the northern Nigeria outbreaks, with no outbreak reported before this time. Inadvertent human introduction or an infected source of feed for the meateating animals within the park may be responsible for such introduction.

Other works [17-19] had similarly refuted the fact that wild water-birds or migratory fowls were primarily responsible for the outbreaks or spread of HPAI H5N1 in Nigeria and other parts of Africa. Infection of wildlife, parks and free-range birds has an ominous implication for other continents as many migratory bird species over-winter in Africa, and West Africa trades wild birds on the international market [20]. Other regions of the world have been infected through migratory birds, and legal and illegal importations [21, 22].

Although the FAO postulated that backyard farms and free-range village birds are at higher risk of infection [23], we found sectors 2 and 3 of the poultry industry (as described by the FAO [23]), which are closely associated with the large-scale importers and hatcheries/distributors of day-old chicks and operate with minimum to no biosecurity, are more widely affected. A more coordinated surveillance system is thus encouraged in the West African subregion in particular and Africa in general to determine the situation of HPAI H5N1 in other countries which currently claim freedom from outbreaks, since all African countries are at high risk of infection.

The role of the different control measures introduced and their contribution to the epidemiology of HPAI H5N1 in Nigeria will also require further evaluation. Control measures were introduced at around week 7 of the outbreaks in Nigeria (20 February 2006), with consequently reduced reports of new infection. However, the effectiveness of the movement restriction was highly questionable as unaffected individual farmers in affected locations sometimes sneak their stock into HPAI-free areas or dispose of them.

High mutation rates represent opportunities for evolution of avian influenza viruses particularly in the
African continent where primary health-care facilities are not easily accessible, human disease monitoring and veterinary infrastructures are doubtful; and hygiene measures in poultry handling/slaughtering are poor. Since the present study analysed the current isolates using HA genes, there is a need to fully characterize all of the Nigerian isolates, conduct more detailed epidemiological research in other parts of Africa, particularly in countries that have not reported outbreaks, and use outcomes to develop better control strategies in view of the fact that the current control policies seem ineffective for the African continent.

In conclusion, Nigeria had widespread infections caused by multiple strains of HPAI H5N1 in 2006 and the introductions were linked to commercial poultry and not wild birds. The infections were human and trade mediated; and the pattern of poultry movement in Nigeria similarly played a role.

\section{ACKNOWLEDGEMENTS}

This work was supported by the financial contributions of ARC-Onderstepoort Veterinary Institute, South Africa; The Department of Production Animal Studies, Faculty of Veterinary Science, University of Pretoria; and The Helena Jooste Bursary and National Veterinary Research Institute, Nigeria. We thank Bontsi Mochotlhoane for technical assistance, and Chika Nwosuh and David Shamaki for assistance in packaging and transportation of isolates to South Africa.

\section{NOTE}

Supplementary material accompanies this paper on the Journal's website (http://journals.cambridge.org).

\section{DECLARATION OF INTEREST}

None.

\section{REFERENCES}

1. Joannis T, et al. Confirmation of H5N1 avian influenza in Africa. Veterinary Record 2006; 158: 309-310.

2. World Organization for Animal Health (http://www. oie.int/eng/info/hebdo/AIS_29.HTM\#Sec12). Accessed 18 June 2007.

3. Nigerian Government (www.worldpoultry.net/news/ id2205-12011/bird_flu_resurfaces_in_kano_nigeria.html). Accessed 27 February 2007. 
4. Ducatez MF, et al. Multiple introduction of H5N1 in Nigeria. Nature 2006; 442: 37.

5. Salzberg SL, et al. Genome analysis linking recent European and African influenza (H5N1) viruses. Emerging Infectious Diseases 2007; 13: 713-718.

6. World Organization for Animal Health. Avian influenza. In: Manual of Diagnostic Tests and Vaccines for Terrestrial Animals. Web edition (http://www.oie.int/ eng/normes/mmanual/A_00037.htm). Accessed 16 July 2007.

7. National Centre for Biotechnology Information. Basic local alignment and search tools (http://www.ncbi. nlm.nih.gov/blast). Accessed 23 May 2007.

8. European Bioinformatics Institute. CLUSTAL-W (http://www.ebi.ac.uk/clustalw/index.html). Accessed on 15 May 2007.

9. Thomson JD, Higgings DG, Gibson TJ. CLUSTAL W : improving the sensitivity of progressive multiple sequence alignment through sequence weighting, position-specific gap penalties and weight matrix choice. Nucleic Acids Research 1994; 22: 4673-4680.

10. Kumar S, Tamura K, Nei M. MEGA3 : Integrated software for molecular evolutionary genetics analysis and sequence alignment. Briefings in Bioinformatics 2004; 5: $150-163$.

11. World Health Organization/World Organization for Animal Health/Food and Animal Organization. Towards a unified nomenclature system for the highly pathogenic H5N1 avian influenza viruses (http://www.who.int/csr/ disease/avian_influenza/guidelines/nomenclature/en/). Accessed 6 May 2008.

12. Ducatez MF, et al. Genetic Characterization of HPAI (H5N1) Viruses from poultry and wild vultures, Burkina Faso. Emerging Infectious Diseases 2007; 13: 611-613.
13. Food and Agricultural Organization (http://www.fao. org/docs/eims/upload//213477/news_birdflu06_en.pdf). Accessed 13 May 2007.

14. Guan Y, et al. H9N2 influenza viruses possessing H5N1like internal genomes continue to circulate in poultry in South Eastern China. Journal of Virology 2000; 74: 9372-9380.

15. Henzler DJ, et al. Epidemiology, production losses, and control measures associated with an outbreak of avian influenza subtype H7N2 in Pennsylvania (1996-1998). Avian Diseases 2003; 47: 1022-1036.

16. Webster RG. Wet markets-a continuing source of severe acute respiratory syndrome and influenza? Lancet 2004; 363: 234-236.

17. Gauthier-Clerc M, Lebarbenchon C, Thomas F. Recent expansion of highly pathogenic avian influenza H5N1 : a critical review. Ibis $2007 ; 149$ : 202-214.

18. Gaidet $\mathbf{N}$, et $\boldsymbol{a l}$. Influenza A viruses in waterbirds in Africa. Emerging Infectious Diseases 2007; 13: 626-629.

19. Feare CJ. The role of wild birds in the spread of avian influenza. Avian Diseases 2007; Published online: 31 July 2007. doi:10.1637/7575-040106.

20. Bird Life International (http://www.birdlife.org/action/ change/cites/grey_parrot_cites_2006.pdf). Accessed 25 May 2007.

21. Sims LD, et al. Origin and evolution of highly pathogenic $\mathrm{H} 5 \mathrm{~N} 1$ avian influenza in Asia. Veterinary Record 2005; 157: 159-164.

22. Van Borm S, et al. Highly pathogenic H5N1 influenza virus in smuggled Thai eagles, Belgium. Emerging Infectious Diseases 2005; 11: 702-705.

23. Food and Agricultural Organization. FAO Recommendations on the Prevention, Control and Eradication of Highly Pathogenic Avian Influenza in Asia. FAO Position Paper, FAO, Rome Italy, 2004, pp. 1-59. 